\title{
In the face of cancer
}

\author{
Cancer Connections \\ Photography exhibition \\ Photosensitive, in partnership with the \\ Canadian Cancer Society \\ Online gallery and travelling exhibition \\ www.photosensitive.com/ \\ May 2008-December 2009
}

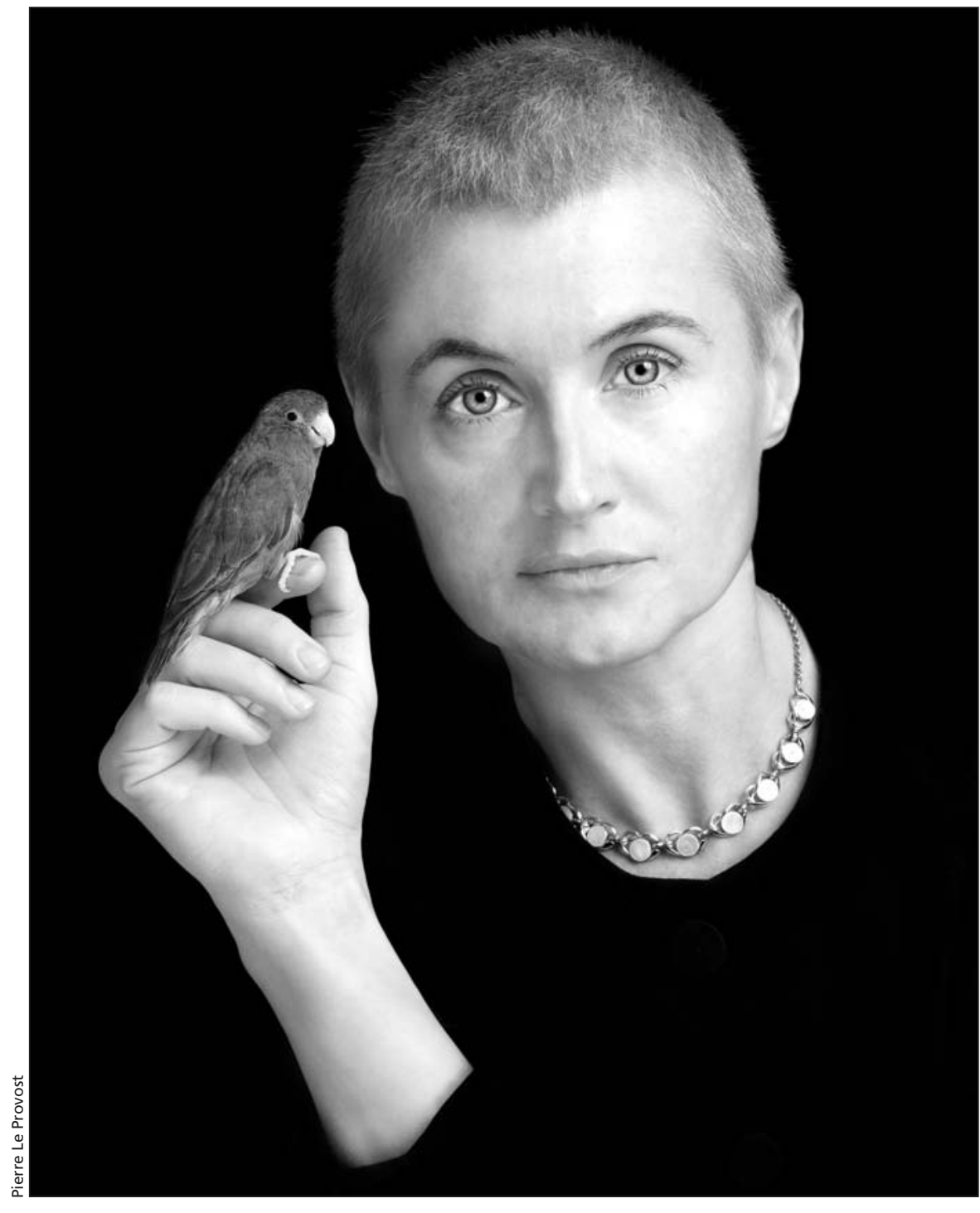

Lorelei beat her cancer years ago. Meeting such a warm-hearted survivor helped Pierre Le Provost, the photographer, to fight and beat his own cancer: "Friends and optimism give you wings," says Le Provost, who lives in Delta, British Columbia.
$\mathrm{E}$ veryday we are saturated with images, most of which we tune out before we even tune in. In most cases it doesn't matter because the images lack any semblance of meaning or relevance to our daily lives. Such is not the case with Cancer Connections, a landmark online gallery and photographic exhibition organized by Photosensitive, in partnership with the Canadian Cancer Society.

Photosensitive is a collective of photographers who have come together to use photography as the means for social change - this exhibit proves true to this professed mandate. With Cancer Connections, Canadians are offered a rare opportunity to participate in documenting one of the scourges of modern society. Ironically, in our otherwise excessively visual world, the portrayal of cancer beyond the superficiality of promotional visuals, is still very much a taboo.

Currently, Cancer Connections consists of more than 400 images taken by 350 photographers, and the show will continue to grow as photographers are encouraged to continue submitting throughout 2009. The locations of live exhibits will be posted online.

The photographs are mostly portraits of people who look just like you and me, except that that they have physical and/or psychological scars from the experience of having lived with, through and in spite of myriad forms of cancer. The people portrayed are patients, survivors, health care workers, friends - in short, what can be loosely called the "cancer community." A short and often poignant descriptive caption, usually identifying the subjects, accompanies each picture.

One of the best features of the website is the clever organization of the images according to relationships: father, mother, aunt, friend, coworker, etc. Click on "mother" and a matrix of 20 thumbnails appears; you can then select one or scroll through the lot. In addition to the organizational merit of this feature, it reinforces the concept of community, for in this show, cancer is definitely not anonymous nor is it ephemeral. The show is about creating connections, and 
cancer is the unfortunate link.

Although the exhibition is uneven, with many of the photographs failing to go beyond the snapshot quality, there are enough compelling images to warrant visiting and lingering on the site.

Ethical considerations have been carefully addressed, with proper consent obtained from each subject. The uncanny result of the consensual photographic moment is that the power of the camera has been harnessed by the person photographed, through the artistry of the person who is photographing. (The photographers are listed alphabetically and can be accessed individually.)

One welcome surprise is that all the pictures are in black and white, which is not only refreshing, but also very effective artistically given the subject. Devoid of moody, honeycoloured lighting, black and white images must rely on content, timing and composition for impact. Some are very dramatic and graphic in tone, not unlike the disease that they document.

The prevalent theme that emerges is the humanity and tenacity of the people who have been forced to come face-toface with cancer. There are the requisite images of bodies scarred by the most invasive of surgeries and the effects of chemotherapy and radiation, but there are also the forlorn smiles of people who have come to terms with their own mortality and the triumphant laughter of many others as if in defiance of death. There are few images of tears and sadness, perhaps because these are usually more intimate moments, and the presence of a witnessing camera can be invasive or awkward at best.

One of the most compelling images is by Aaron Vincent Elkaim, of a young woman applying eyeliner in a mirror, her head hairless, smooth and shiny. Her eyes have a penetratingly deep gaze that is not easily forgotten. For people who are unaccustomed to seeing pictures of patients with cancer, this is a particularly unsettling image, for she is doing something rather ordinary, but in extraordinarily trying circumstances.

Equally unsettling is the image by Rick Collins, of a woman lying dead on a hospital gurney, surrounded by her friends and loved ones. They have just spent hours on her hair and makeup for the funeral, and as the grieving friends stare at her body, there is an eerily

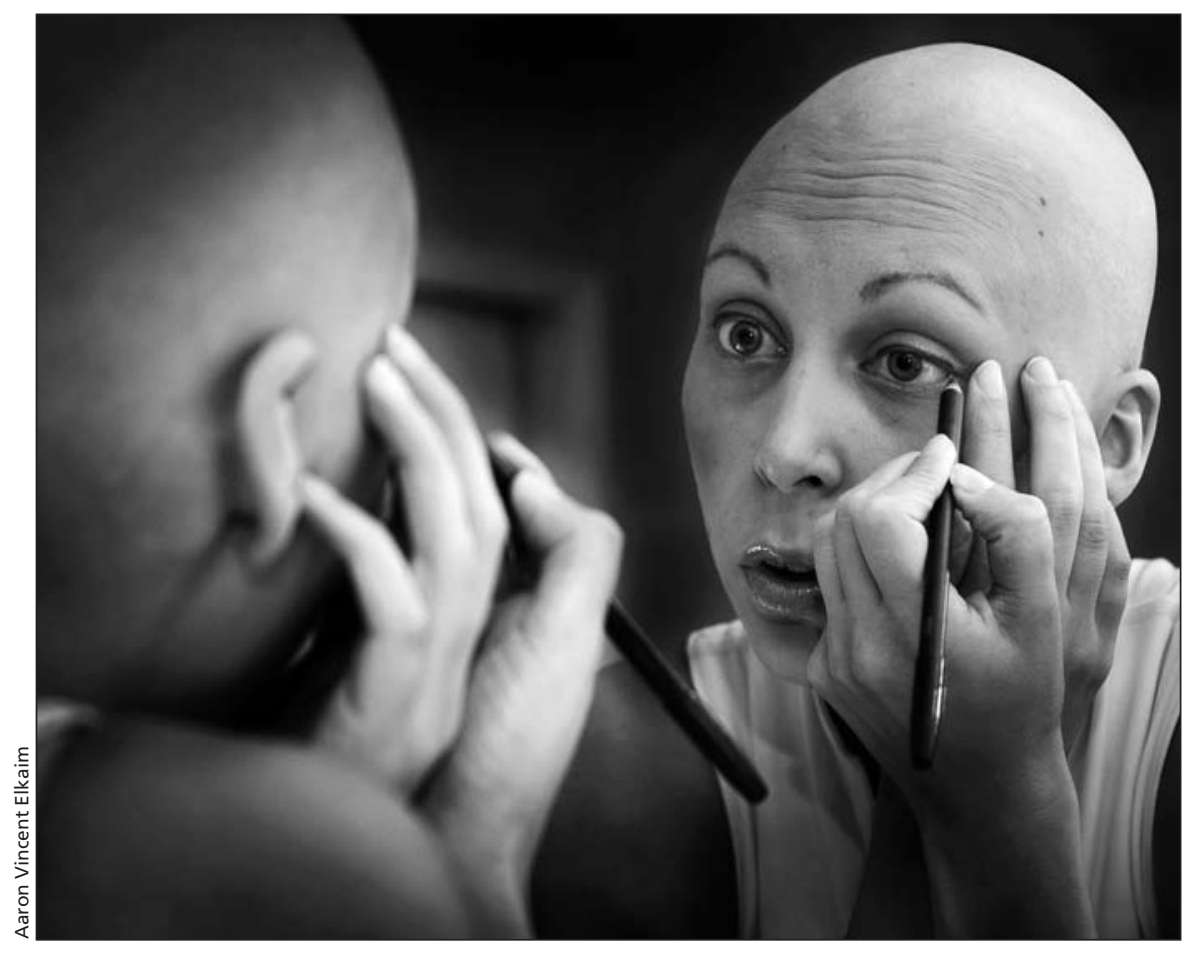

Erin was diagnosed with breast cancer at 24. Now 26, she has been pronounced terminally ill, but continues to explore alternative treatments. Photographer Aaron Vincent Elkaim lives in Winnipeg, Manitoba.

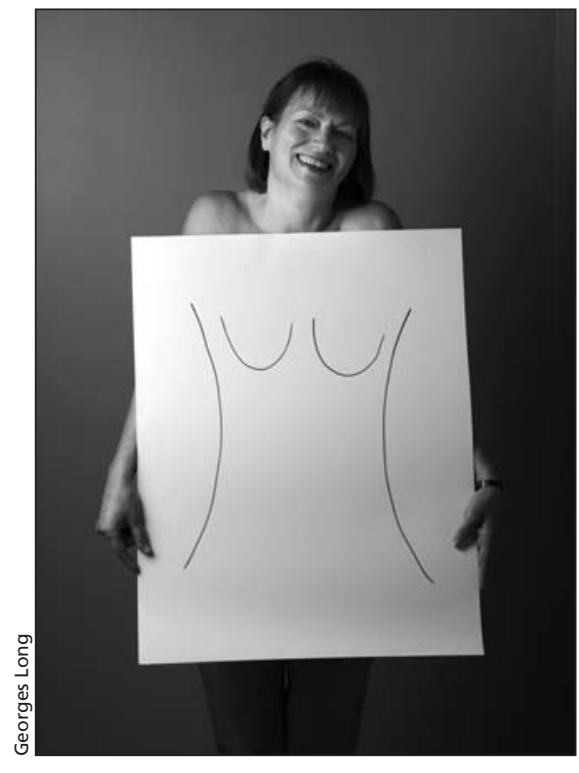

Anne Duguay, diagnosed with ductal carcinoma in situ, was photographed the day before her mastectomy surgery. Anne lost a sister to breast cancer some years ago. At the shoot she said, "I want a picture of myself with my real twins one last time." Photographer Georges Long lives in Fredericton, New Brunswick.

quiet feeling, almost as if they were in a ritualistic trance.

The word "death" is actually never used in any of the texts, only the euphemism "passed away," reflecting our discomfort with death. But the majority of the images are positive, portraying the invincible human spirit, such as the portrait by Pierre Le Provost of a woman holding a budgie. She has beaten cancer, and she exudes serenity, so much so that meeting her helped the photographer, Pierre Le Provost, fight and beat his own cancer. In his words, "friends and optimism give you wings." This exhibition gives you inspiration.

\section{Vincenzo Pietropaolo}

Photographer and author Toronto, Ont.

Mr. Pietropaolo is currently finishing the book, Invisible No More, a photographic chronicle of people with intellectual disabilities (Rutgers, Spring 2010).

Online extra: The author's preferred photos appear at http://www.cmaj.ca/cgi/content /full/180/6/646/DC1 